\title{
Comparative Oil Composition Study of the Endemic Moroccan Olive (Olea europaea subsp. maroccana) and Wild Olive (var. Sylvestris) in Central West Morocco
}

\author{
Sara Elgadi (iD), ${ }^{1,2}$ Ahmed Ouhammou $\left(\mathbb{D},{ }^{1}\right.$ Hamza Zine $\mathbb{D}^{1},{ }^{1}$ Nadia Maata, ${ }^{3}$ \\ Rachid Ait Babahmad $\mathbb{D}^{1},{ }^{1}$ and Abderraouf El Antari $\mathbb{C l}^{2}$ \\ ${ }^{1}$ Laboratory of Microbial Biotechnology, Agrosciences and Environment, Faculty of Sciences-Semlalia, Cadi Ayyad University, \\ BP. 2390, 40 000, Marrakech, Morocco \\ ${ }^{2}$ Laboratory of Agro, Food Technology and Quality, Regional Center for Agronomic Research of Marrakech, \\ National Institute of Agronomic Research (INRA), Marrakech, Morocco \\ ${ }^{3}$ Official Laboratory for Chemical Analysis and Research (LOARC), Casablanca, Morocco \\ Correspondence should be addressed to Sara Elgadi; sara.elgadi@ced.uca.ma
}

Received 18 August 2020; Revised 29 December 2020; Accepted 23 January 2021; Published 2 February 2021

Academic Editor: Francisca Hernández

Copyright $\odot 2021$ Sara Elgadi et al. This is an open access article distributed under the Creative Commons Attribution License, which permits unrestricted use, distribution, and reproduction in any medium, provided the original work is properly cited.

\begin{abstract}
Six wild olive subspecies (Olea europaea L.) are currently recognised globally, with two taxa cooccurring in the argan tree area in Central West Morocco: the widespread Mediterranean subspecies europaea var. Sylvestris (the so-called oleaster) and the microendemic subspecies maroccana. Despite its taxonomic and ecological importance, the chemical composition of subsp. maroccana oil remains poorly known. Therefore, the aim of this study is to investigate the oil content and the chemical composition of subsp. maroccana and var. Sylvestris as well as comparing their proprieties during two consecutive years (2017 and 2018) from the same geographical area. The fatty acid and the sterol compositions were analysed using gas chromatography. Additionally, the tocopherol content was determined using high-performance liquid chromatography. The total amount of unsaturated fatty acids was higher in maroccana $(85.24 \%)$ than that in oleasters $(79.05 \%)$. Additionally, the tocopherol and phytosterol content of the maroccana oil $(1232.35 \mathrm{mg} / \mathrm{kg}$ and $312.75 \mathrm{mg} / 100 \mathrm{~g}$, resp.) was approximately twofold higher than in oleasters $(661.35 \mathrm{mg} / \mathrm{kg}$ and $210.06 \mathrm{mg} / 100 \mathrm{~g}$, resp.). Analysis of variance and principal component analysis (PCA) of the chemical composition highlighted a significant difference between the quantitative and qualitative properties of their oil. Finally, these findings suggest that maroccana oil could be considered as a potential source of vitamin E, essential fatty acids, and sterols and can provide a nutraceutical oil for the local population. While this work contributes to the study of olive tree biodiversity, further investigations are still necessary to guide the putative nutraceutical use of subspecies maroccana.
\end{abstract}

\section{Introduction}

Morocco is an extraordinary hotspot for plant diversity and endemism [1]. Many emblematic trees species exist in Morocco; one of the most remarkable species is Olea europaea L. which belongs to the Oleaceae. This tree has two forms: cultivated Olea europaea L. subsp. europaea var. europaea and wild O. europaea subsp. europaea var. sylvestris (Mill.) Lehr. [2]. Wild olive trees are subdivided into six subspecies: europaea L. guanchica P. Vargas et al., cerasiformis (Webb. \& Berth.) Kunkel \& Sunding, laperrinei (Batt.
\& Trab.) Cif, cuspidata (Wall. ex G. Don) Cif, and maroccana (Greuter \& Burdet) P. Vargas et al. [3]. O. europaea subsp. maroccana (OEM) is an endemic tree to Morocco that exists in small and fragmented stands in the Western High Atlas, especially in Ida Outanane mountainous region [4] and constitutes a unique Moroccan olive tree population $[5,6]$. This tree grows in the occurrence area of the Moroccan argan tree ((Argania spinosa (L.) Skeels) [5], which is characterised by high plant biodiversity, due to their arid and semiarid climate with frequently oceanic influences [7]. According to Fennane et al. [4] and Médail et al. [5], ssp. 
maroccana grows in very limited areas and has some distinctive morphological characteristics: the tree is $1-4 \mathrm{~m}$ tall, the leaf is $40-70 \mathrm{~mm}$ long and $6-11 \mathrm{~mm}$ wide, the petiole is very short $(0.2-0.7 \mathrm{~cm})[4,5]$, and the drupes are globular to ovoid in shape with a relatively small size, ranging from $0.5-0.7$ to $0.9-1.1 \mathrm{~cm}$ [5]. Subspecies maroccana blooms 30 to 40 days after ssp. europaea [5] and does not hybridise probably, and Kassa et al. [3] linked this to the phenological differentiation and high ploidy level (hexaploid). Wild olive trees (oleasters), on the other hand, are very common in Morocco and massively grow in the north and central Moroccan plains [8]. The length of their leaves is 1.5-5 times longer than larger, whereas the maroccana leaves are known to be 5-12 times longer than wider [4].

In Morocco, olive trees are cultivated over an area of approximately 1,070,000 ha, with the dominance of one cultivar (currently named "Zitoun Beldi" or "Picholine Marocaine"), which represents $96 \%$ of trees [9]. Olive oil is known by its good taste and high nutritional value, and it is considered one of the essential ingredients of the Mediterranean diet [10]. Indeed, several studies have shown that the composition of olive oil makes it beneficial for human health [11]. Olive oil is composed of a predominant fatty acid, monounsaturated oleic acid (up to $83 \% \mathrm{w} / \mathrm{w}$ ) [12], and several phenolic compounds, phytosterols, and tocopherols that constitute the unsaponifiable fraction [13]. Compared to people consuming sunflower oil, it has been reported by Soriguer et al. [14] that people consuming olive oil are at a lower risk of obesity and hypertriglyceridemia and have lower high-density lipoprotein cholesterol levels. In addition, it is known that monounsaturated fatty acids reduce cardiovascular mortality [15]. Furthermore, tocopherols contribute to the prevention of cardiovascular diseases and certain types of cancer [16]. As mentioned in Bouarroudj et al. [17] and Dabbou et al. [18] olive oil from wild trees contain higher amounts of phenols, tocopherols, and antioxidants compared to cultivated olive. Thus, the outcomes of investigating for new subspecies especially those occurring under arid and semiarid conditions can eventually present an interesting potential source for cultivar genetic amelioration and further expand its therapeutic and nutraceutical potential for the local population although these crops resist well to marginal conditions.

To the authors' knowledge, no study has yet assessed the quality or chemical composition of subsp. maroccana oil. In this respect, the present study aims to investigate and compare the oil content, the quality indices, and the chemical composition, particularly fatty acid, tocopherol, and sterol between two Olea europaea subspecies: subsp. maroccana (OEM) and subsp. europaea var. sylvestris (OES) cooccurring in the same environmental conditions.

\section{Materials and Methods}

2.1. Plant Material. In general, subspecies maroccana is located in the Western High Atlas of Morocco, especially in the Ida Outanane mountainous region $\left(30^{\circ} 39 \mathrm{~N} 9^{\circ} 09 \mathrm{~W}\right.$; $751 \mathrm{~m}$ ), on a clay-sand substrate. O. e. subsp. europaea var. sylvestris (OES) samples were also collected in the same region $\left(30^{\circ} 34 \mathrm{~N}^{\circ} 20 \mathrm{~W} ; 620 \mathrm{~m}\right)$. Specimens' identification of Olea (Figure 1) was carried out through their characters (habit, vigor, leaf density, and length of internodes), leaf characters (shape, length, and width), inflorescence, fruit, and endocarp characters. This identification was conducted in the fieldwork and confirmed by the use of local Floras and monographs. It was also in reference to the exsiccatae (collection of dried herbarium specimens) at Regional Herbarium of "MARK," Cadi Ayyad University. All samples were collected randomly by hand from 20 adult trees at full maturity for each subspecies. Fruit sampling was performed for two successive years (December 2017 and December 2018). Precipitation in the year 2017 was $186.88 \mathrm{~mm}$, lower compared to the year 2018, $312.78 \mathrm{~mm}$. Rainfall data of the study area has been downloaded from Worldclim [19].

2.2. Olive Oil Extraction. Oil was extracted within $24 \mathrm{~h}$ of harvesting using an Abencor system. Olive drupes were washed and crushed; the paste obtained was submitted to malaxation for $30 \mathrm{~min}$ and centrifuged at $3500 \mathrm{rpm}$. Then, after the oil was decanted, it was preserved in dark glass bottles in a refrigerator at $4^{\circ} \mathrm{C}$, filled with nitrogen to avoid oxidation.

2.3. Chemicals. All chemicals used for the determination of free acidity, spectroscopic UV indices (K232, K270), and peroxide value were purchased from Sigma (St. Louis, MO, USA). The internal standard, $5 \alpha$-cholestanol, the fatty acid methyl esters (FAME) standard mixture, and tocopherol ( $\alpha$, $\gamma$, and $\delta$-tocopherols) were purchased from Sigma (St. Louis, MO, USA). Silica gel plate for thin-layer chromatography was purchased from Fluka (Buchs, Switzerland). Acetone, methanol, cyclohexane, ethanol, chloroform, petroleum ether, and diethyl ether were purchased from Carlo Erba (Milan, Italy).

2.4. Physicochemical Quality Parameters. Free acidity (expressed as \% oleic acid), spectrophotometric UV indices (K232, K270), peroxide value given as milliequivalents of active oxygen per kilogram of oil $\left(\mathrm{meqO}_{2} / \mathrm{kg}\right)$, and oil content (\%) were determined according to ISO 660 (2009) [20], ISO 3656 (2002) [21], ISO 3960 (2007) [22], and ISO 659 (2009) [23], respectively.

\subsection{Chemical Composition}

2.5.1. Fatty Acids. The analytical method for the determination of fatty acid composition was described in regulation to the European Union standard methods [24], using $1 \mathrm{~g}$ of oil sample, $2 \mathrm{~mL}$ of petroleum ether, and $3 \mathrm{~mL}$ of a methanolic potassium hydroxide solution $(2 \mathrm{M})$. The methyl esters mixture was analysed by Gas Chromatography (CG, Varian CP 3380) equipped with a capillary column (CP-Wax $52 \mathrm{CB} L=30 \mathrm{~m} ; \Phi=0.25 \mathrm{~mm}$; and $\varnothing=0.20 \mu \mathrm{m}$ ). The injector temperature was set at $220^{\circ} \mathrm{C}$, and the temperatures of the flame ionisation detector (FID) and oven were maintained at 


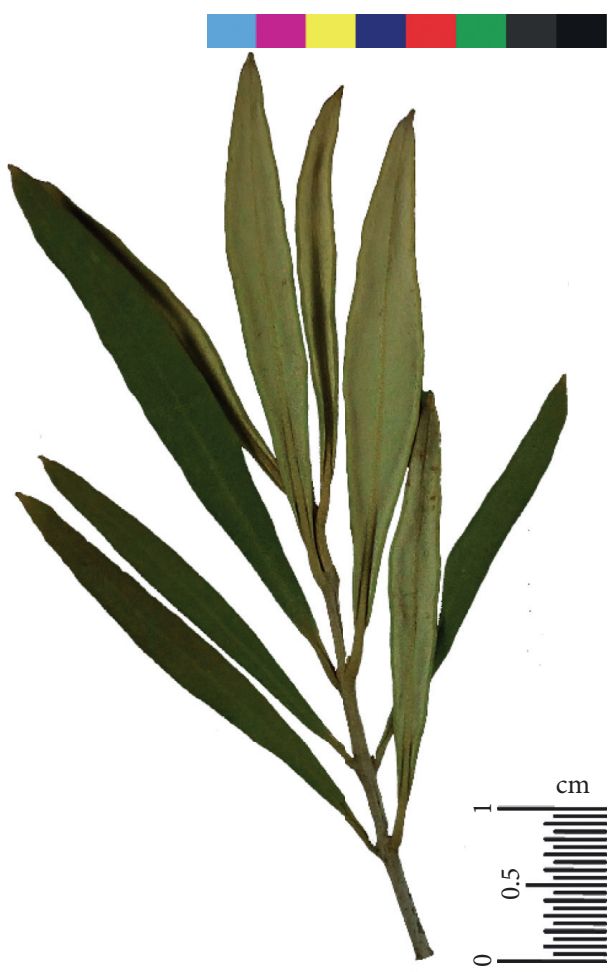

(a)

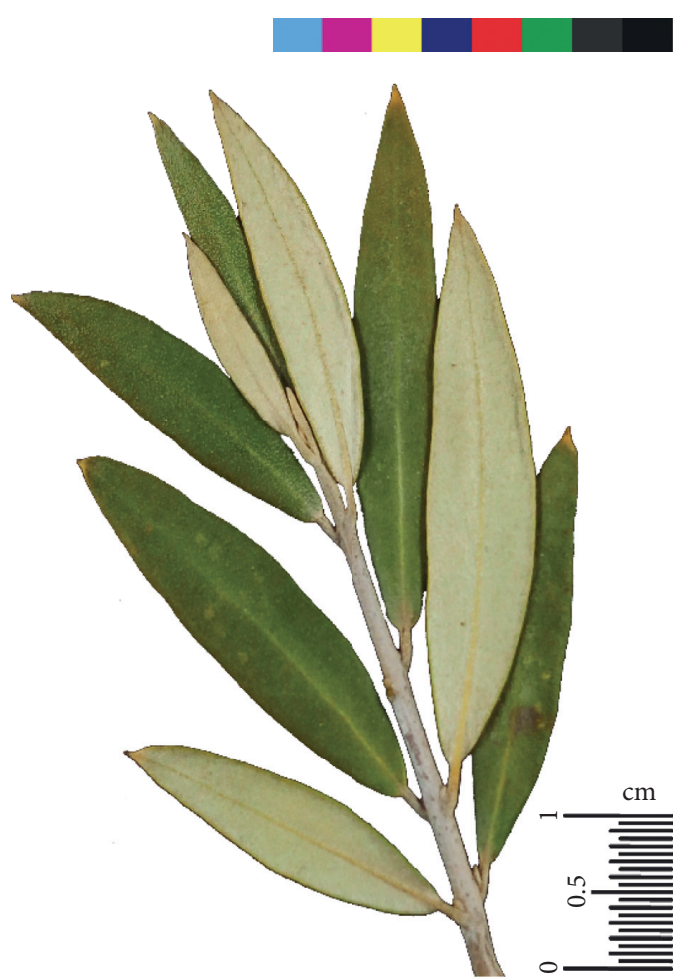

(b)

Figure 1: Branch of (a) subsp. maroccana (OEM) and (b) O. e. subsp. europaea var. sylvestris (OES).

$230^{\circ} \mathrm{C}$ and $190^{\circ} \mathrm{C}$ respectively, with nitrogen used as the carrier gas.

2.5.2. Tocopherols. According to ISO 9936 [25], $1 \mathrm{~g}$ of oil was dissolved in $25 \mathrm{~mL}$ of isooctane/isopropanol $(99: 1, \mathrm{v} / \mathrm{v})$ and then analysed using high-performance liquid chromatography (Shimadzu LC-10 HPLC system) with a detector type RF-10AXL HPLC Fluorescence Detector (Shimadzu, Columbia, MD), and LiChrospher Si 60 column $(L=250 \mathrm{~mm}$, $\Phi=4.6 \mathrm{~mm}, \varnothing=5 \mu \mathrm{m})$.

2.5.3. Phytosterols. The content of individual sterols and total sterols was determined according to a method described by Skiada et al. [26]. Trimethylsilylation of the sterol fraction was analysed according to the IOC method [27] using a gas chromatograph (HP 6890, Agilent Technologies, Santa Clara, CA, USA) equipped with a flame ionisation detector and capillary column (Agilent VF-5 ms $L=30 \mathrm{~m}$, $\Phi=0.32 \mathrm{~mm}, \emptyset=0.25 \mu \mathrm{m}) V$ with fused silica from Agilent Technologies (Palo Alto, CA, USA).

2.6. Statistical Analysis. All data were reported as the mean \pm standard deviation (SD), of at least three analytical determinations on three replicated samples. Differences between the means were assessed using one-way analysis of variance (ANOVA) followed by Duncan's multiple range test. ANOVA was performed using SPSS Statistics version 21 (IBM Corp, Armonk, NY, USA), with $p$ values $\leq 0.05$ considered statistically significant. Furthermore, principal component analysis (PCA) was applied to study the relations between the two subspecies on the chemical composition. The data matrix consisted of individuals (olive oil samples) and variables (fatty acids, tocopherols, and phytosterols composition). The PCA was processed using $R$ software version 3.6.2 ( $\mathrm{R}$ Foundation for Statistical Computing, Vienna, AT).

\section{Results and Discussion}

3.1. Physicochemical Quality Parameters. It was found that the oil content (\% dry matter) of ssp. maroccana is in the range of $5.32-5.46 \%$, which is low in comparison to that of var. Sylvestris (8.65-9.10\%). Compared to the results obtained by Hannachi et al. [28], the oil content of O. europaea subsp. cuspidata from Kenya was found to be in the range of $5.0-7.7 \%$, similar to the oil content of ssp. maroccana. In addition, the oil content of var. sylvestris from Tunisia was found to reach up to $8.02-15.06 \%$, the same as that of var. sylvestris from Morocco. Subsp. maroccana and var. sylvestris showed very lower oil contents comparatively with Moroccan Picholine 38.5-48\% [29]. According to the IOC standards, olive oils extracted from OEM (O. europaea subsp. maroccana) and OES belong to the category of extra virgin olive oils (Table 1) [30]. In addition, it was found that the free acidity of the OEM and OES oils does not exceed the upper limit of $0.8 \%$. The UV absorption coefficients (K232, K270) and peroxide value also confirmed that both oils are within the limit values of the IOC: K232 $\leq 2.5$, K270 $\leq 0.22$, 
TABLE 1: Oil content and quality indices of subsp. maroccana (OEM) and O. e. subsp. europaea var. sylvestris (OES) oils compared to EVOO for two successive years, 2017 and 2018.

\begin{tabular}{lccccc}
\hline & \multicolumn{2}{c}{ OEM $(N=20)$} & \multicolumn{2}{c}{ OES $(N=20)$} & EVOO (IOC. 2019) \\
& 2017 & 2018 & 2017 & 2018 & \\
Oil content (\% dry matter) & $5.32 \pm 0.01 \mathrm{a}$ & $5.46 \pm 0.07 \mathrm{a}$ & $8.65 \pm 0.11 \mathrm{~b}$ & $9.10 \pm 0.20 \mathrm{c}$ & \\
Free fatty acid (\%) & $0.30 \pm 0.02 \mathrm{a}$ & $0.33 \pm 0.02 \mathrm{a}$ & $0.30 \pm 0.01 \mathrm{a}$ & $0.31 \pm 0.02 \mathrm{a}$ & $\leq 0.80$ \\
K232 & $2.32 \pm 0.01 \mathrm{c}$ & $2.08 \pm 0.04 \mathrm{~b}$ & $2.03 \pm 0.02 \mathrm{~b}$ & $1.89 \pm 0.04 \mathrm{a}$ & $\leq 2.50$ \\
K270 & $0.14 \pm 0.03 \mathrm{~b}$ & $0.12 \pm 0.01 \mathrm{ab}$ & $0.09 \pm 0.03 \mathrm{a}$ & $0.10 \pm 0.02 \mathrm{ab}$ & $\leq 0.22$ \\
Peroxide value (meqO2/kg oil) & $3.41 \pm 0.10 \mathrm{c}$ & $2.66 \pm 0.07 \mathrm{~d}$ & $6.38 \pm 0.12 \mathrm{a}$ & $5.21 \pm 0.09 \mathrm{~b}$ & $\leq 20$ \\
\hline
\end{tabular}

Values are expressed as mean \pm SD. Different letters in the same line designate significant differences $(p<0.05)$. K232 and K270: ultraviolet specific extinction at 232 and $270 \mathrm{~nm}$.

and peroxide value $\leq 20 \mathrm{mEqO}_{2} / \mathrm{kg}$ oil. A significant difference was revealed in the oil content of var. sylvestris between the years of harvest; it can be explained by the high rate of precipitation for the second year [31]. It should be noted that the results obtained for the physicochemical parameters coincided with those obtained by Bouarroudj et al. [17] and Dabbou et al. [18].

\subsection{Chemical Composition}

3.2.1. Fatty Acids. As shown in Table 2, oleic acid was found to be predominant in both ssp. maroccana and var. sylvestris oils, but with a higher value $(67.79 \%)$ in var. sylvestris oil, followed by palmitic acid (18.66\%) and linoleic acid (8.20\%). However, the opposite was true for ssp. maroccana oil, which has a low value of palmitic acid (10.65\%) and the highest value observed of linoleic acid (19.81\%). Linoleic acid can be used as a marker for ssp. maroccana oil. In OEM, except for the value of linolenic acid, all values were within the limits established by the IOC (2019) [30]. Similar results to those of ssp. maroccana oil were noted in the oil of O. europaea subsp. cuspidata from Kenya, in which the level of oleic acid was the highest $(44.3 \%)$, followed by linoleic acid (33.3\%) and palmitic acid (12.1\%) [30]. Similar results to those of var. sylvestris oil were also noted in several studies in Algeria [17], Tunisia [18], Spain [32], and Italy [33]. All fatty acids studied exhibited a significant difference between the composition of OEM and OES. A difference between the years of harvest was also noted, except for C16:1, C18:1, C20:0, and C20:1 for ssp. maroccana oil and $\mathrm{C} 18: 2, \mathrm{C} 18: 3$, and unsaturated fatty acid (UFA) for var. sylvestris oil. A cultivar can show different technological potentialities from one environment to another; this characteristic is known to play an important role in improving the fatty acid composition of the oil: this is what makes it possible to define geographical origins [34]. It was also found that ssp. maroccana oil is more unsaturated than var. sylvestris oil and, hence, can be considered a source of UFAs and a very important factor against cardiovascular diseases [15].

Principal component analysis (PCA) showed the score plot of PCA for subsp. maroccana (OEM) and var. sylvestris (OES) for two successive years, 2017 (17) and 2018 (18), according to their fatty acid composition (Figure 2). The first two principal components are significant and explain $90.4 \%$ of the total inertia. PC1 (Dim1) presents $83.9 \%$ of the total inertia, whereas PC2 (Dim2) presents 6.5\%. Most of the points for OEM17 and OEM18 were pointed to the left of PC1, meaning that OEM17 and OEM18 had large negative loadings on dimension 1 . On the other hand, points for OES17 and OES18 are presented on the right of PC1, meaning that they had large positive loadings on dimension 1. According to parameters contribution (Figures 2(a) and 2(b)) C18:0, C18:2, C20:0, and C20:1 could be considered as markers for ssp. maroccana oil and C16:0 for var. sylvestris oil. The impact of the harvest year was not very significant for OEM while the groups were distinct for OES. Subsp. maroccana and var. sylvestris were collected in the same region. Hence, the PCA has revealed a distinct separation between the two subspecies according to their fatty acid composition.

3.2.2. Tocopherols. It should be noted that the total tocopherol value obtained from ssp. maroccana oil (1272 mg/ $\mathrm{kg}$ ) is twice as high as that obtained from var. sylvestris oil $(683 \mathrm{mg} / \mathrm{kg}$; Table 3). The results also showed that ssp. maroccana oil is rich in $\alpha$ - and $\beta$-tocopherols (1058.96-985.92 mg/kg and $188.63-177.86 \mathrm{mg} / \mathrm{kg}$, resp.), with levels twice as high compared to the levels in var. sylvestris oil (533.96-496.91 mg/kg and $34.33-32.75 \mathrm{mg} / \mathrm{kg}$, resp.). Moreover, the values of $\gamma$-tocopherol and $\delta$-tocopherol in var. sylvestris oil were found to be 37.50 and $77.21 \mathrm{mg} / \mathrm{kg}$, respectively, which are higher than the values found in ssp. maroccana oil (13.24 and $11.86 \mathrm{mg} / \mathrm{kg}$, resp.). Significant variations between the years of harvest were noted for $\alpha$-tocopherols, $\beta$-tocopherols, and total tocopherols in ssp. maroccana and for $\gamma$-tocopherol and $\delta$-tocopherol in var. sylvestris. Compared with the literature, lower values than those obtained from ssp. maroccana oil have been found. This high content of tocopherols is a good indicator for olive oils and has great benefits for human health [12]. On the other hand, the oil content of var. sylvestris from Tunisia was found to be close to that obtained by Baccouri et al. [35] (309.5-781.8 mg/kg) and higher than that obtained from Algerian wild olive $(170-320 \mathrm{mg} / \mathrm{kg})[36]$ and cultivated olive trees $(84-463 \mathrm{mg} / \mathrm{kg}$ ) [37]. It should be noted that the climatic conditions can also influence the tocopherol content especially $\alpha$-tocopherol and $\beta$-tocopherol for ssp. maroccana and $\gamma$-tocopherol and $\delta$-tocopherol for var. sylvestris which were significantly high in 2017, considered as a dry year in comparison with 2018 [38]. 
TABLE 2: Fatty acid composition (\%) of subsp. maroccana (OEM) and O. e. subsp. europaea var. sylvestris (OES) for two successive years, 2017 and 2018.

\begin{tabular}{|c|c|c|c|c|c|c|}
\hline & \multirow{2}{*}{ Fatty acid } & \multicolumn{2}{|c|}{ OEM $(N=20)$} & \multicolumn{2}{|c|}{ OES $(N=20)$} & \multirow{2}{*}{ EVOO (IOC, 2019) } \\
\hline & & 2017 & 2018 & 2017 & 2018 & \\
\hline Palmitic acid & $\mathrm{C} 16: 0$ & $10.65 \pm 0.03 a$ & $10.89 \pm 0.07 b$ & $18.66 \pm 0.06 c$ & $19.02 \pm 0.01 \mathrm{~d}$ & $7.50-20.00$ \\
\hline Palmitoleic acid & $\mathrm{C} 16: 1 \omega 7$ & $0.65 \pm 0.00 a$ & $0.65 \pm 0.01 \mathrm{a}$ & $2.52 \pm 0.01 b$ & $2.57 \pm 0.00 c$ & $0.30-3.50$ \\
\hline Margaric acid & C17: 0 & $0.09 \pm 0.01 c$ & $0.08 \pm 0.02 c$ & $0.01 \pm 0.00 \mathrm{a}$ & $0.04 \pm 0.00 \mathrm{~b}$ & $\leq 0.4$ \\
\hline Margaroleic acid & $\mathrm{C} 17: 1$ & $0.05 \pm 0.01 \mathrm{ab}$ & $0.03 \pm 0.01 \mathrm{a}$ & $0.09 \pm 0.01 c$ & $0.07 \pm 0.00 \mathrm{bc}$ & $\leq 0.6$ \\
\hline Stearic acid & $\mathrm{C} 18: 0$ & $3.30 \pm 0.00 c$ & $3.29 \pm 0.02 c$ & $1.99 \pm 0.08 \mathrm{a}$ & $2.16 \pm 0.08 b$ & $0.50-5.00$ \\
\hline Oleic acid & $\mathrm{C} 18: 1 \omega 9$ & $63.22 \pm 0.07 a$ & $63.54 \pm 0.25 a$ & $67.79 \pm 0.14 c$ & $67.26 \pm 0.08 b$ & $55.0-83.0$ \\
\hline Linoleic acid & $\mathrm{C} 18: 2$ & $19.81 \pm 0.00 c$ & $19.19 \pm 0.16 b$ & $8.20 \pm 0.02 \mathrm{a}$ & $8.13 \pm 0.01 \mathrm{a}$ & $2.50-21.00$ \\
\hline Linolenic acid & $\mathrm{C} 18: 3$ & $1.26 \pm 0.03 b$ & $1.37 \pm 0.05 c$ & $0.75 \pm 0.00 \mathrm{a}$ & $0.74 \pm 0.00 \mathrm{a}$ & $\leq 1.00$ \\
\hline Arachidic acid & $\mathrm{C} 20: 0$ & $0.60 \pm 0.00 \mathrm{~b}$ & $0.60 \pm 0.00 \mathrm{~b}$ & $0.00 \pm 0.00 \mathrm{a}$ & $0.00 \pm 0.00 \mathrm{a}$ & $\leq 0.60$ \\
\hline Gadoleic acid & $\mathrm{C} 20: 1$ & $0.35 \pm 0.00 \mathrm{~b}$ & $0.35 \pm 0.00 \mathrm{~b}$ & $0.00 \pm 0.00 \mathrm{a}$ & $0.00 \pm 0.00 \mathrm{a}$ & $\leq 0.50$ \\
\hline Unsaturated fatty acid & UFA & $85.35 \pm 0.04 c$ & $85.14 \pm 0.05 b$ & $79.34 \pm 0.14 \mathrm{a}$ & $78.76 \pm 0.09 a$ & \\
\hline Saturated fatty acid & SFA & $14.65 \pm 0.04 \mathrm{a}$ & $14.85 \pm 0.05 \mathrm{a}$ & $20.66 \pm 0.14 b$ & $21.22 \pm 0.09 c$ & \\
\hline Unsaturated fatty acid/saturated fatty acid & UFA/SFA & $5.82 \pm 0.02 \mathrm{~d}$ & $5.73 \pm 0.02 c$ & $3.84 \pm 0.03 b$ & $3.71 \pm 0.02 \mathrm{a}$ & \\
\hline
\end{tabular}

Values are expressed as mean \pm SD. Different letters in the same line designate significant differences $(p<0.05)$.
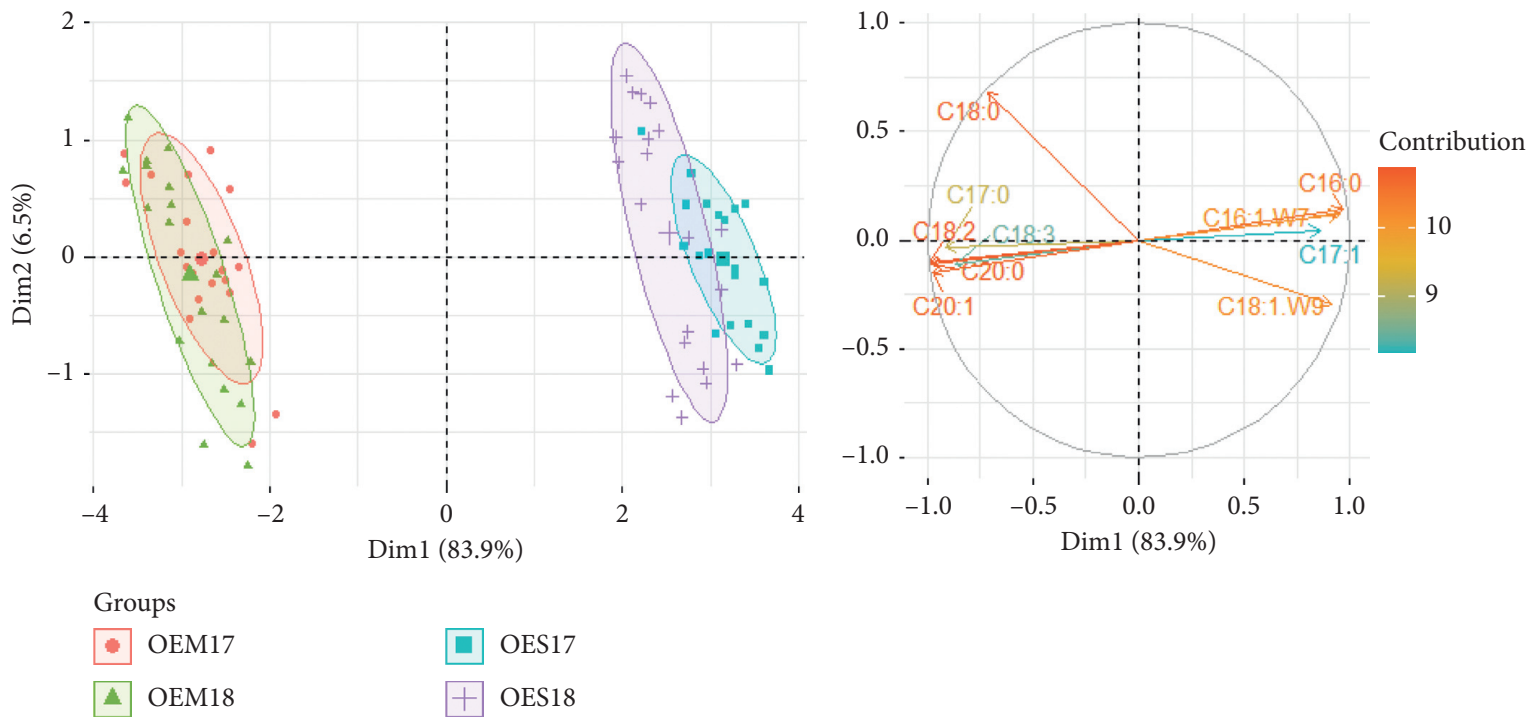

(a)

(b)

FIgURE 2: (a) Scores and (b) loading plots with principal component analysis (PCA) for subsp. maroccana (OEM) and O. e. subsp. europaea var. sylvestris (OES) for two successive years, 2017 (17) and 2018 (18), according to their fatty acid composition.

TABLE 3: Tocopherol composition (mg/kg) of Olea europaea subsp. maroccana (OEM) and O. e. subsp. europaea var. sylvestris (OES) during 2017 and 2018.

\begin{tabular}{lcccccc}
\hline & & $\alpha$-Tocopherol & $\beta$-Tocopherol & $\gamma$-Tocopherol & $\delta$-Tocopherol & Total tocopherols \\
\hline \multirow{2}{*}{ OEM $(N=20)$} & 2017 & $1058.96 \pm 26 \mathrm{c}$ & $188.63 \pm 3 \mathrm{c}$ & $13.24 \pm 0.14 \mathrm{a}$ & $11.86 \pm 0.09 \mathrm{a}$ & $1272.70 \pm 29.23 \mathrm{c}$ \\
& 2018 & $985.92 \pm 32 \mathrm{~b}$ & $177.86 \pm 5 \mathrm{~b}$ & $17.16 \pm 0.22 \mathrm{a}$ & $11.06 \pm 0.13 \mathrm{a}$ & $1192.00 \pm 37.35 \mathrm{~b}$ \\
\hline \multirow{2}{*}{ OES $(N=20)$} & 2017 & $533.96 \pm 13 \mathrm{a}$ & $34.33 \pm 1.37 \mathrm{a}$ & $37.50 \pm 1.24 \mathrm{c}$ & $77.21 \pm 1.98 \mathrm{c}$ & $683.00 \pm 17.59 \mathrm{a}$ \\
& 2018 & $496.91 \pm 7 \mathrm{a}$ & $32.75 \pm 1.09 \mathrm{a}$ & $37.05 \pm 1.15 \mathrm{~b}$ & $72.99 \pm 1.66 \mathrm{~b}$ & $639.70 \pm 10.92 \mathrm{a}$ \\
\hline
\end{tabular}

Values are expressed as mean \pm SD. Different letters in the same row indicate significant differences $(p<0.05)$.

Figure 3 shows the score plot of PCA for subsp. maroccana and var. sylvestris during two successive years, 2017 and 2018, according to their tocopherol composition. The first two principal components are very significant and explain $99.8 \%$ of the total inertia. PC1 (Dim1) presents
99.6\% of the total inertia. However, PC2 (Dim2) presents $0.2 \%$. Most of the points for OEM17 and OEM18 were pointed to the left of PC1, meaning that OEM17 and OEM18 had large negative loadings on dimension 1 . On the other hand, points for OES17 and OES18 are presented on the 


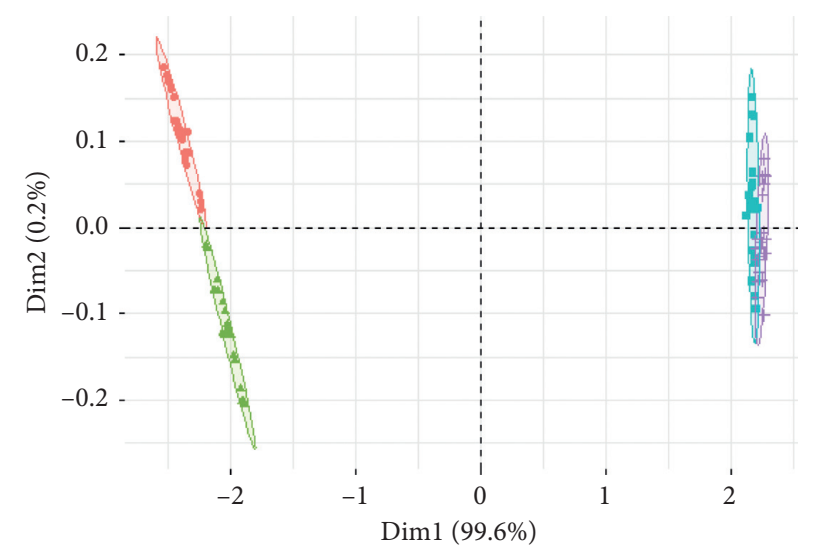

Groups

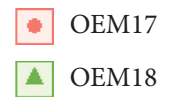

OES17

OES18

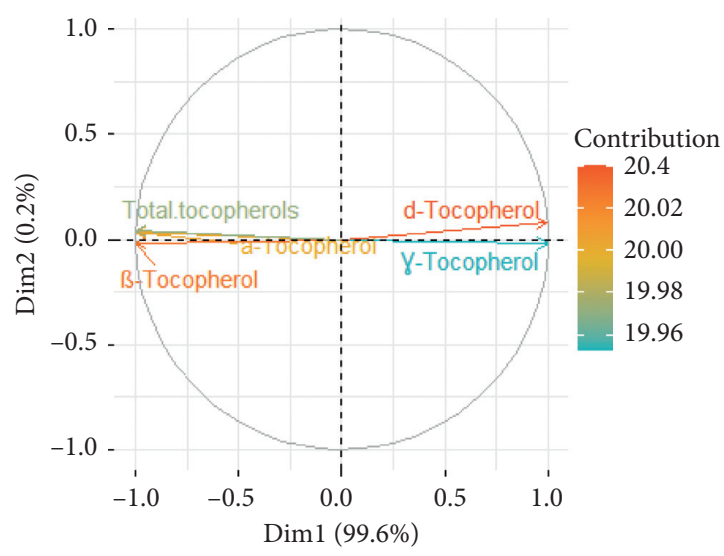

(a)

(b)

FIGURE 3: (a) Scores and (b) loading plots with principal component analysis (PCA) for subsp. maroccana (OEM) and O. e. subsp. europaea var. sylvestris (OES) for two successive years, 2017 (17) and 2018 (18), according to their tocopherol composition.

right of PC1, meaning that they had large positive loadings on dimension 1. Parameters contribution (Figures 3(a) and $3(\mathrm{~b}))$ revealed that $\delta$-tocopherol could be considered as a marker for var. sylvestris oil while $\alpha$ - and $\beta$-tocopherols could be used as markers for ssp. maroccana oil. The impact of the harvest year was not very significant for var. sylvestris although the groups were distinct for subsp. maroccana: OEM17 in the positive loadings on dimension 2 and OEM18 in the negative loadings on dimension 2. The PCA was revealed a distinct separation between the two subspecies according to their tocopherols composition which confirming a strong botanical effect.

3.2.3. Phytosterols. The content of total sterols was found to be higher in ssp. maroccana oil $(269.35-356.15 \mathrm{mg} / 100 \mathrm{~g})$ than in var. sylvestris oil (207.23-212.9 mg/100 g). It was also found that ssp. maroccana oil had the highest content of $\beta$-sitosterol (87.33-88.31\%), $\Delta$-7-stigmastenol (0.68-0.72\%), and $\Delta$-5,24-stigmastadienol $(0.32-0.35 \%)$. On the other hand, var. sylvestris oil was found to have a high content of 24-methylene-cholesterol (0.09-0.13\%) and $\Delta-5$-avenasterol (4.29-5.37\%). However, no differences were observed regarding the levels of campestanol (Table 4). Significative differences were revealed between years in the majority of sterol compounds except for 24-methylene-cholesterol for ssp. maroccana and $\Delta-5,24$-stigmastadienol for both oils. Similar to what was found by Hannachi et al. [39], $\beta$-sitosterol is the major sterol, with a content in the range of $75.7-84.72 \%$, in var. sylvestris oil. Additionally, $\Delta-7$-stigmastenol can be considered a specific marker for ssp. maroccana oil [26]. Nevertheless, it was found that the total sterol content of var. sylvestris oil from Tunisia ranges from 1079.35 to $2068.17 \mathrm{mg} / \mathrm{kg}$ [40]. These values are close to those of total sterols obtained from var. sylvestris oil but still lower than those obtained from ssp. maroccana oil. In addition, the total sterol content in Portuguese olive oil was found to be in the range of $2003-2682 \mathrm{mg} / \mathrm{kg}$ [41], whereas that of Moroccan Picholine was found to be in the range of $1794.60-2038 \mathrm{mg} / \mathrm{kg}[34,35]$.

The PCA in Figure 4 was performed to discriminate subsp. maroccana and var. sylvestris oils according to their sterolic profile. The first two principal components explain approximately $54.2 \%$ of the total variance. PC1 (Dim1) presents $41.6 \%$ of the total inertia. However, PC2 (Dim2) presents $12.6 \%$. Most of the points for OEM17 and OEM18 were pointed to the left of PC1, meaning that OEM17 and OEM18 had large negative loadings on dimension 1. Furthermore, OEM17 was pointed in the positive loadings on dimension 2 and OEM18 in the negative loadings on dimension 2 implying that the impact of the harvest year was significant. Dissimilar to subsp. maroccana, it was observed that most of the var. sylvestris points are shown to the right of PC1 and had large positive loadings on dimension 1. Figure 4(b) shows that $\Delta$-5-avenasterol and 24-methylenecholesterol had a high contribution and could be considered as markers for var. sylvestris oil. Furthermore, total sterols, $\Delta$-7-stigmastenol, and $\Delta$-5,24-stigmastadienol could be used as markers for subsp. maroccana oil. Similar to subsp. maroccana, the harvest year was significant on phytosterol composition of var. sylvestris. OEM and OES were clearly discriminated according to phytosterol composition.

In order to have a precise overview of the oil composition of subsp. maroccana and var. sylvestris, a combined principal component analysis was performed using fatty acid, tocopherol, and sterol as variables (Figure 5). The first two principal components explain $73.5 \%$ of data variation. Most of the points for subsp. maroccana were pointed to the left of PC1, meaning that OEM had large negative loadings on dimension 1. Furthermore, var. sylvestris points are shown to the right of $\mathrm{PC} 1$ and had large positive loadings on dimension 1. Figure 5(b) shows that C18:2, C20:0, C20:1, 
TABLE 4: Phytosterol content in mg/100 g and the phytosterol composition (\%) of Olea europaea subsp. maroccana (OEM) and O. e. subsp. europaea var. sylvestris (OES).

\begin{tabular}{lccccc}
\hline \multirow{2}{*}{ Sterols } & \multicolumn{2}{c}{ OEM $(N=20)$} & \multicolumn{2}{c}{ OES $(N=20)$} & EVOO (IOC, 2019) \\
& 2017 & 2018 & 2017 & 2018 & \\
\hline Total sterols $(\mathrm{mg} / 100 \mathrm{~g})$ & $356.15 \pm 7.56 \mathrm{c}$ & $269.35 \pm 5.66 \mathrm{~b}$ & $207.23 \pm 6.23 \mathrm{a}$ & $212.9 \pm 8.8 \mathrm{a}$ & \\
Cholesterol & $0.36 \pm 0.01 \mathrm{c}$ & $0.32 \pm 0.03 \mathrm{~b}$ & $0.30 \pm 0.02 \mathrm{ab}$ & $0.28 \pm 0.01 \mathrm{a}$ & $\leq .00$ \\
24-Methylene-cholesterol & $0.05 \pm 0.00 \mathrm{a}$ & $0.05 \pm 0.01 \mathrm{a}$ & $0.13 \pm 0.01 \mathrm{~b}$ & $0.09 \pm 0.01 \mathrm{c}$ & $\leq .5 \%$ \\
Campesterol & $3.69 \pm 0.02 \mathrm{ab}$ & $3.22 \pm 0.22 \mathrm{a}$ & $4.48 \pm 0.03 \mathrm{c}$ & $3.76 \pm 0.46 \mathrm{~b}$ & $<.0 \%$ \\
Campestanol & $0.07 \pm 0.00 \mathrm{~ns}$ & $0.05 \pm 0.00 \mathrm{~ns}$ & $0.06 \pm 0.00 \mathrm{~ns}$ & $0.06 \pm 0.00 \mathrm{~ns}$ & $<\mathrm{campesterol}$ \\
Stigmasterol & $1.42 \pm 0.01 \mathrm{~b}$ & $1.26 \pm 0.03 \mathrm{a}$ & $1.67 \pm 0.02 \mathrm{~d}$ & $1.52 \pm 0.05 \mathrm{c}$ & \\
Clerosterol & $1.09 \pm 0.01 \mathrm{c}$ & $1.12 \pm 0.01 \mathrm{~d}$ & $1.00 \pm 0.01 \mathrm{~b}$ & $0.98 \pm 0.01 \mathrm{a}$ & \\
$\beta$-Sitosterol & $87.33 \pm 0.07 \mathrm{ab}$ & $88.31 \pm 1.67 \mathrm{~b}$ & $85.43 \pm 0.05 \mathrm{a}$ & $86.67 \pm 1.10 \mathrm{ab}$ & \\
Sitostanol & $0.96 \pm 0.03 \mathrm{~b}$ & $1.55 \pm 0.04 \mathrm{~d}$ & $0.63 \pm 0.02 \mathrm{a}$ & $1.36 \pm 0.03 \mathrm{c}$ & \\
$\Delta$-5-Avenasterol & $3.35 \pm 0.04 \mathrm{~b}$ & $2.50 \pm 0.05 \mathrm{a}$ & $5.37 \pm 0.02 \mathrm{~d}$ & $4.29 \pm 0.23 \mathrm{c}$ & \\
$\Delta$-5,24-Stigmastadienol & $0.35 \pm 0.01 \mathrm{~b}$ & $0.32 \pm 0.10 \mathrm{~b}$ & $0.10 \pm 0.00 \mathrm{a}$ & $0.14 \pm 0.09 \mathrm{a}$ & \\
$\Delta$-7-Stigmastenol & $0.72 \pm 0.01 \mathrm{~d}$ & $0.68 \pm 0.01 \mathrm{c}$ & $0.24 \pm 0.00 \mathrm{a}$ & $0.26 \pm 0.01 \mathrm{~b}$ & \\
$\Delta$-7-Avenasterol & $0.61 \pm 0.00 \mathrm{ab}$ & $0.62 \pm 0.00 \mathrm{~b}$ & $0.61 \pm 0.00 \mathrm{ab}$ & $0.59 \pm 0.01 \mathrm{a}$ & \\
Apparent $\beta$-sitosterol ${ }^{*}$ & $93.45 \pm 0.16 \mathrm{ab}$ & $94.16 \pm 0.54 \mathrm{c}$ & $92.67 \pm 0.10 \mathrm{a}$ & $93.56 \pm 0.17 \mathrm{~b}$ & \\
\hline
\end{tabular}

${ }^{*}$ Apparent $\beta$-sitosterol $=$ clerosterol $+\beta$-sitosterol + sitostanol $+\Delta$-5-avenasterol $+\Delta-7$-stigmastenol. N.S.: not significant. The statistical significance level was $p<0.05$.
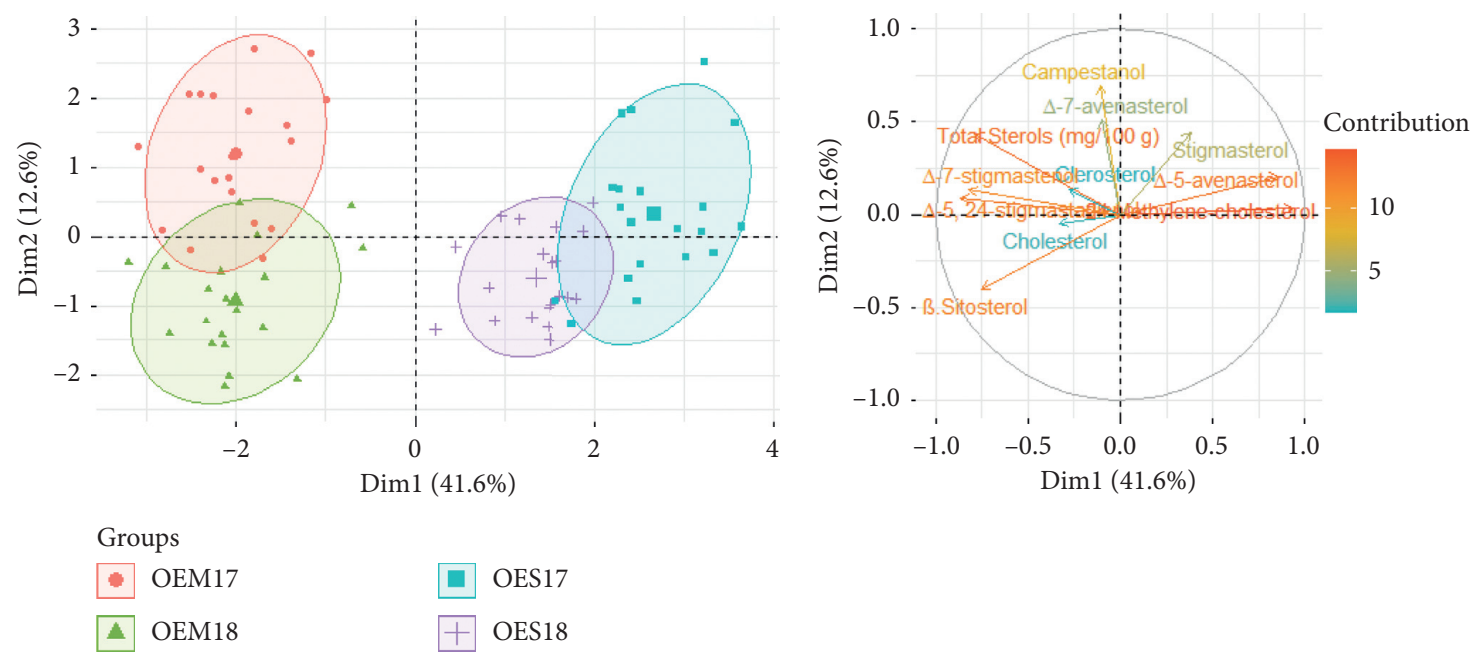

(a)

(b)

FIGURE 4: (a) Scores and (b) loading plots with principal component analysis (PCA) for subsp. maroccana (OEM) and $O$ e. subsp. europaea var. sylvestris (OES) for two successive years, 2017 (17) and 2018 (18), according to their phytosterol composition.

$\alpha$ - and $\beta$-tocopherols, total tocopherols, and total sterols had a high contribution and could be considered as markers for subsp. maroccana. On the other hand, C16:0, $\gamma$ - and $\delta$-tocopherol, $\Delta$-5-avenasterol, and 24-Methylene-cholesterol had a high contribution for var. sylvestris oil and could be considered as markers. The impact of the harvest year was significant for both oils. Therefore, the PCA of chemical composition data revealed a discrete separation between subsp. maroccana and var. sylvestris, by creating distinctive clusters. 


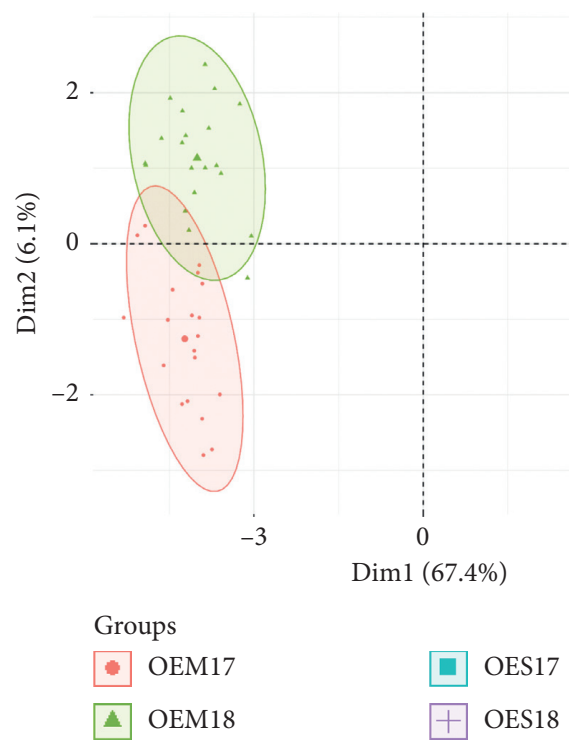

(a)

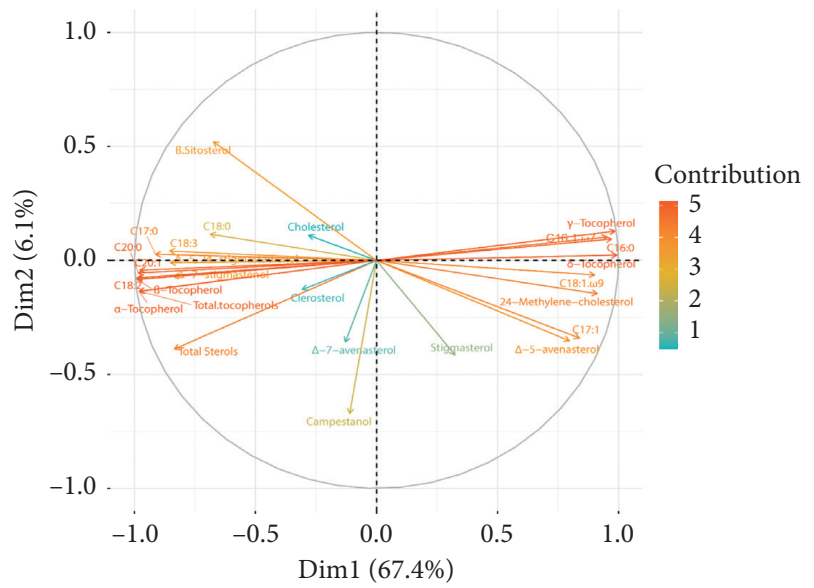

(b)

FIGURE 5: (a) Scores and (b) loading plots with principal component analysis (PCA) for subsp. maroccana (OEM) and O. e. subsp. europaea var. sylvestris (OES) for two successive years, 2017 (17) and 2018 (18), according to the combination of fatty acid, tocopherol, and phytosterol composition.

\section{Conclusions}

The clear distinction was recorded on secondary traits (chemical composition) between the subspecies studied confirming the morphological differentiation. The oil content of subsp. maroccana is lower than var. sylvestris. A significant difference was found in the chemical compositions of the olive oils from ssp. maroccana and var. sylvestris. In fact, several compounds can be considered as specific markers for the distinction between the chemical composition of olive oil. The total unsaturated fatty acid (UFA) content, especially linoleic acid (essential fatty acids), of ssp. maroccana oil was found to be higher than that of var. sylvestris oil. Furthermore, the tocopherol content in ssp. maroccana oil was found to be twofold higher than the value obtained for var. sylvestris oil, with notable richness in $\alpha$ and $\beta$-tocopherols. In addition, the phytosterol content was also found to be higher in ssp. maroccana oil than in var. sylvestris oil. Therefore, to better exploit this natural resource, additional studies on other quality and purity parameters are necessary to complete the characterisation and identify the potential and performance of ssp. maroccana and var. sylvestris in Central West Morocco. [42, 43]

\section{Data Availability}

The data used to support the findings of this study are available from the corresponding author upon request.

\section{Conflicts of Interest}

The authors declare that they have no conflicts of interest.

\section{Acknowledgments}

Special thanks are due to the staff of the Laboratory for Chemical Analysis especially Mr. M. Amakhmakh for his valuable assistance and the staff of the Laboratory of AgroFood Technology and Quality (INRA-Marrakech) especially Mrs. M. Lachguer. The authors would like to thank Dr. A. Diarra, Mr E. Radouane (Ph.D. Student), and Dr. A. Aghraz for their advice.

\section{References}

[1] S. Lala, A. Amri, and N. Maxted, "Towards the conservation of crop wild relative diversity in North Africa: checklist, prioritisation and inventory," Genetic Resources and Crop Evolution, vol. 65, no. 1, pp. 113-124, 2018.

[2] P. Vargas and J. W. Kadereit, "Molecular fingerprinting evidence (issr, inter-simple sequence repeats) for a wild status of olea europaea 1. (Oleaceae) in the eurosiberian north of the iberian peninsula," Flora, vol. 196, no. 2, pp. 142-152, 2001.

[3] A. Kassa, H. Konrad, and T. Geburek, "“Molecular diversity and gene flow within and among different subspecies of the wild olive (Olea europaea L.): a review," Flora: Morphology, Distribution, Functional Ecology of Plants, vol. 250, pp. 18-26, 2019.

[4] M. Fennane, M. Ibn Tattou, J. Mathez, A. Ouyahya, and J. El Oualidi, Flore pratique du Maroc manuel de détermination des plantes vasculaires, Institut Scientifique-Université, Rabat, Morocco, 1999.

[5] F. Médail, P. Quézel, G. Besnard, and B. Khadari, "Systematics, ecology and phylogeographic significance of Olea europaea L. ssp. maroccana (Greuter \& Burdet) P. Vargas et al., a relictual olive tree in south-west Morocco," Botanical Journal of the Linnean Society, vol. 137, no. 3, pp. 249-266, 2001. 
[6] G. Besnard, B. Khadari, P. Baradat, and A. Bervillé, "Combination of chloroplast and mitochondrial DNA polymorphisms to study cytoplasm genetic differentiation in the olive complex (Olea europaea L.)," Theoretical and Applied Genetics, vol. 105, no. 1, pp. 139-144, 2002.

[7] F. Msanda, A. El Aboudi, and J. Peltier, "Biodiversité et biogéographie de l'arganeraie marocaine," Cahiers Agricultures, vol. 14, no. 4, pp. 357-364, 2005.

[8] L. Emberger, Aperçu général sur la végétation du Maroc: commentaire de la carte phytogéographique du Maroc 1: 1.500. 000, 1939.

[9] MAPMDREF, “(Ministère de l'Agriculture, de la Pêhe Maritime, du Développement Rural et des Eaux et Forêts-Morocco)," 2020.

[10] H. Diraman and H. Dibeklioğlu, "Characterization of Turkish virgin olive oils produced from early harvest olives," JAOCS, Journal of the American Oil Chemists' Society, vol. 86, no. 7, pp. 663-674, 2009.

[11] A. El Antari, A. El Moudni, and H. Ajana, "Comparaison de la qualité et de la composition acide de l'huile d'olive de certaines variétés méditerranéennes cultivées au Maroc," Olivae, vol. 95, pp. 26-31, 2003.

[12] M. Gorzynik-debicka, P. Przychodzen, F. Cappello et al., "Potential health benefits of olive oil and plant polyphenols," International Journal of Molecular Science, vol. 19, 2018.

[13] M.-I. Covas, V. Ruiz-Gutierrez, and R. De La Torre, "Minor components of olive oil: evidence to date of health benefits in humans," International Life Sciences Institute, vol. 9, no. 2, pp. 161-180, 2005.

[14] F. Soriguer, G. Rojo-Martinez, A. Goday, E. Bordiu, R. Carmena, and E. Ortega, "Olive oil has a beneficial effect on impaired glucose regulation and other cardiometabolic risk factors . di@bet.es study," European Journal of Clinical Nutrition, vol. 67, pp. 911-916, 2013.

[15] L. Schwingshackl and G. Hoffmann, "Monounsaturated fatty acids and risk of cardiovascular disease: synopsis of the evidence available from systematic reviews and meta-analyses," Nutrients, vol. 4, no. 12, pp. 1989-2007, 2012.

[16] F. Shahidi and A. C. De Camargo, "Tocopherols and tocotrienols in common and emerging dietary Sources: occurrence, applications , and health benefits," International Journal of Molecular Science, vol. 17, no. 10, p. 1745, 2016.

[17] K. Bouarroudj, A. Tamendjari, and R. Larbat, "Quality, composition and antioxidant activity of Algerian wild olive (Olea europaea L. subsp. Oleaster) oil," Industrial Crops and Products, vol. 83, pp. 484-491, 2016.

[18] S. Dabbou, S. Dabbou, R. Selvaggini et al., "Comparison of the chemical composition and the organoleptic profile of virgin olive oil from two wild and two cultivated Tunisian olea europaea," Chemistry \& Biodiversity, vol. 8, no. 1, pp. 189-202, 2011.

[19] S. E. Fick and R. J. Hijmans, "WorldClim 2: new 1-km spatial resolution climate surfaces for global land areas," International Journal of Climatology, vol. 37, no. 12, pp. 4302-4315, 2017.

[20] Polish Consumer-Santandertrade, ISO 660, "Animal and Vegetable Fats and Oils-Determination of Acid Value and Acidity", Polish Consumer-Santandertrade, Warsaw, Poland, 2009.

[21] International Organization for Standardization, ISO 3656, "Animal and vegetable fats and oils-determination of ultraviolet absorbance expressed as specific UV extinction,", International Organization for Standardization, Geneva, Switzerland, 2002.
[22] International Organization for Standardization, ISO 3960, "animal and vegetable fats and oils-determination of peroxide value-iodometric (visual) endpoint determination,", International Organization for Standardization, London, UK, 2007.

[23] International Organization for Standardization, ISO 659, "Oilseeds-Determination of Oil Content (Reference Method)", International Organization for Standardization, Geneva, Switzerland, 2009.

[24] Commission Regulation (EEC), "No. 2568/91 of 14 July 1991 on the characteristics of olive oil and olive-residue oil and on the relevant methods of analysis," Official Journal of the European Union, vol. 208, pp. 1-8, 1991.

[25] International Organization for Standardization, ISO 9936, "Animal and vegetable fats and oils-determination of tocopherols and tocotrienols contents-method using high performance liquid chromatography, International Organization for Standardization, Geneva, Switzerland, 1997.

[26] V. Skiada, P. Tsarouhas, and T. Varzakas, "Comparison and discrimination of two major monocultivar extra virgin olive oils in the southern region of peloponnese, according to specific compositional/traceability markers," Foods, vol. 9, no. 2, p. 155, 2020.

[27] International Olive Council, "IOC," Determ. Sterol Compos. Content Alcohol. Compd. by Capill. Gas Chromatogr.vol. COI/ T.20/, 2018.

[28] H. Hannachi, H. Sommerlatte, C. Breton, and M. Msallem, "Oleaster (var. sylvestris) and subsp . cuspidata are suitable genetic resources for improvement of the olive (olea europaea subsp . europaea var. europaea)," Genetic Resources and Crop Evolution, vol. 56, pp. 393-403, 2009.

[29] S. El Qarnifa, A. El Antari, and A. Hafidi, "Effect of maturity and environmental conditions on chemical composition of olive oils of introduced cultivars in Morocco," Journal of Food Quality, vol. 2019, Article ID 1854539, 14 pages, 2019.

[30] International Olive Council, "IOC," Int. Trade Stand. Appl. to Olive Oils Olive-Pomace Oils, vol. 3, pp. 1-17, 2019.

[31] B. Alowaiesh, Z. Singh, Z. Singh, and S. G. Kailis, "Harvesting time influences fruit removal force, moisture, oil content, free fatty acids and peroxide in the oil of Frantoio and Manzanilla olive cultivars," Australian Journal of Crop Science, vol. 10, no. 12, pp. 1662-1668, 2016.

[32] L. León, R. De La Rosa, L. Velasco, and A. Belaj, "Using wild olives in breeding programs: implications on oil quality composition," Frontiers in Plant Science, vol. 9, pp. 1-9, 2018.

[33] N. G. Criscuolo, F. Guarino, C. Angelini, and I. National, "High biodiversity arises from the analyses of ancient olive trees of south of italy," Plants (Basel), vol. 8, no. 9, p. 297, 2019.

[34] H. Hannachi, M. Msallem, S. Ben Elhadj, and M. El Gazzah, "Influence du site géographique sur les potentialités agronomiques et technologiques de l'olivier (Olea europaea L.) en Tunisie," Comptes Rendus Biologies, vol. 330, no. 2, pp. 135-142, 2007.

[35] B. Baccouri, "06_Composition virgin olive," Grasas Y Aceites, vol. 59, no. 4, pp. 346-351, 2008.

[36] S. Boucheffa, A. Tamendjari, P. Rovellini, and S. Venturini, "Composition and antioxidant activity of some Algerian wild extra virgin olive oils," Rivista Italiana delle Sostanze Grasse, vol. 91, no. 3, pp. 177-185, 2014.

[37] G. Beltrán, A. Jiménez, C. Del Rio et al., "Variability of vitamin $\mathrm{E}$ in virgin olive oil by agronomical and genetic factors," Journal of Food Composition and Analysis, vol. 23, no. 6, pp. 633-639, 2010.

[38] S. Dabbou, S. Sifi, I. Rjiba et al., "Effect of pedoclimatic conditions on the chemical composition of theSigoiseOlive 
cultivar," Chemistry \& Biodiversity, vol. 7, no. 4, pp. 898-908, 2010.

[39] H. Hannachi, N. Nasri, W. Elfalleh, N. Tlili, A. Ferchichi, and M. Msallem, "Fatty acids, sterols, polyphenols, and chlorophylls of olive oils obtained from Tunisian wild olive trees (olea europaeaL. Var.Sylvestris)," International Journal of Food Properties, vol. 16, no. 6, pp. 1271-1283, 2013.

[40] B. Baccouri, H. Manai, J. S. Casas, E. Osorio, and M. Zarrouk, “"Industrial Crops \& Products Tunisian wild olive (Olea europaea L . subsp. oleaster) oils: sterolic and triterpenic dialcohol compounds," Industrial Crops and Products, vol. 120, pp. 11-15, 2018.

[41] M. R. Alves, S. C. Cunha, J. S. Amaral, J. A. Pereira, and M. B. Oliveira, "Classification of PDO olive oils on the basis of their sterol composition by multivariate analysis," Analytica Chimica Acta, vol. 549, no. 1-2, pp. 166-178, 2005.

[42] A. Bajoub, E. Hurtado-fernández, E. A. Ajal, and A. Fernández-Gutiérrez, "Quality and chemical profiles of monovarietal north Moroccan olive oils from "Picholine Marocaine" cultivar : registration database development and geographical discrimination," Food Chemistry, vol. 179, pp. 127-136, 2015.

[43] Y. El Kharrassi, N. Maata, M. A. Mazri et al., "Chemical and phytochemical characterizations of argan oil (Argania spinosa L. skeels), olive oil (Olea europaea L. cv. Moroccan picholine), cactus pear (Opuntia megacantha salm-dyck) seed oil and cactus cladode essential oil," Journal of Food Measurement and Characterization, vol. 12, no. 2, pp. 747-754, 2018. 